\title{
Case Report - A Rare Case of SLE Retinopathy
}

\author{
Heena Dharamdasani ${ }^{1}$, Stephen Sudhakar ${ }^{2}$ \\ 1,2 Department of Ophthalmology, Chettinad Hospital and Research Institute, Kelambakkam, Tamil Nadu, India.
}

\section{INTRODUCTION}

Systemic lupus erythematosus (SLE) is an autoimmune connective tissue disorder. It has a relapsing and remitting course. ${ }^{1}$ It is found to be more common in Asian and African population. It is more common in females than males. Usual age of onset is between 15 years and 45 years. ${ }^{2}$ It occurs in one third of patients with SLE and is associated with morbidity. SLE can involve eyes, joints, brain, kidney, skin, serosa, ears, lung, and gastrointestinal tract. Manifestations in SLE occur due to recurrent vascular injury, which is secondary to immune complex deposition, thrombosis, leukothrombosis. ${ }^{3}$

Thrombotic complications are found to be more common in Caucasians. ${ }^{4}$ Ocular manifestations can be seen in one third of the population with SLE. 1,5 Triggering factors such as exposure to sunlight, use of sulphonamides, pregnancy, infections, and contraception have been known to exacerbate the disease..$^{2,6}$

Hallmarks of ophthalmic involvement in SLE include severe tear deficiency, retinal vasculopathy and scleral inflammation. ${ }^{3}$ Most common ocular presentation is keratoconjunctivitis sicca. ${ }^{7}$

Fundus examination in the eye is the only part of the body where the vasculature can be directly visualized and hence SLE retinopathy indicates the amount of systemic vascular damage, retinopathy indicates high disease activity in patients with SLE and hence indicates a poor survival of these patients. ${ }^{2}$ Most patients with SLE develop secondary Sjogren's syndrome.

\section{PRESENTATION OF CASE}

A 24 year old female patient came with complaints of defective vision in both eyes since 10 days, recently diagnosed as SLE 1 month ago. On presentation her BCVA in right eye was $6 / 6$ and left eye was $6 / 9$. Anterior segment in both eyes were within normal limits. Fundus examination in right eye showed Normal disc, arteriolar attenuation, cotton wool spots in inferior and superior arcuate pattern around macula, foveal reflex present (Figure: 1). Left eye showed normal disc, arteriolar attenuation with venous irregularities, cotton wool spots at the macula, scattered micro aneurysms at macula, dot haemorrhages superior to macula, foveal reflex present (figure: 2). Oct macula showed macular oedema in both eyes (Figure: 3, Figure: 4).

Fundus fluorescin angiography (FFA) showed right eye arteriolar and venular blockage in macula with collaterals (Figure 5). Left eye showed arteriolar and venular blockage in macula with ghost vessels extending temporally, Retinal ischemia temporally (Figure 6). Patient was started on Hydroxychloroquine (HCQ) BD, oral prednisolone, which was gradually tapered, Tab. acetazolamide $250 \mathrm{mg}$ BD x 1 week, eye drops nepafenac TDS, left eye inferior and temporal Pan retinal photocoagulation (PRP) was done. After 8 months' patient came with sudden, painless loss of vision in the right eye, both eyes anterior segment was normal, Colour vision was defective in both eyes. Right eye showed central vitreous haemorrhage obscuring disc and macula (Figure 7). Left eye showed disc pallor present, posterior vitreous detachment (PVD) present, vitreous band present superior to the disc, macula FR dull, arteriolar attenuation present, laser marks present inferiorly and temporally, sheathing of veins nasally (Figure 8).
Corresponding Author:

Dr. Stephen Sudhakar,

Department of Ophthalmology,

Chettinad Hospital and Research

Institute, Kelambakkam,

Tamil Nadu, India.

E-mail:dr_stephen1978@yahoo.com

DOI: $10.14260 / \mathrm{jemds} / 2021 / 382$

How to Cite This Article:

Dharamdasani H, Sudhakar S. Case report a rare case of SLE retinopathy. J Evolution Med Dent Sci 2021;10(24):1848-1851, DOI: 10.14260/jemds/2021/382

Submission 11-02-2021,

Peer Review 19-04-2021,

Acceptance 26-04-2021,

Published 14-06-2021.

Copyright (c) 2021 Heena Dharamdasani et al. This is an open access article distributed under Creative Commons Attribution License [Attribution 4.0 International (CC BY 4.0)] 


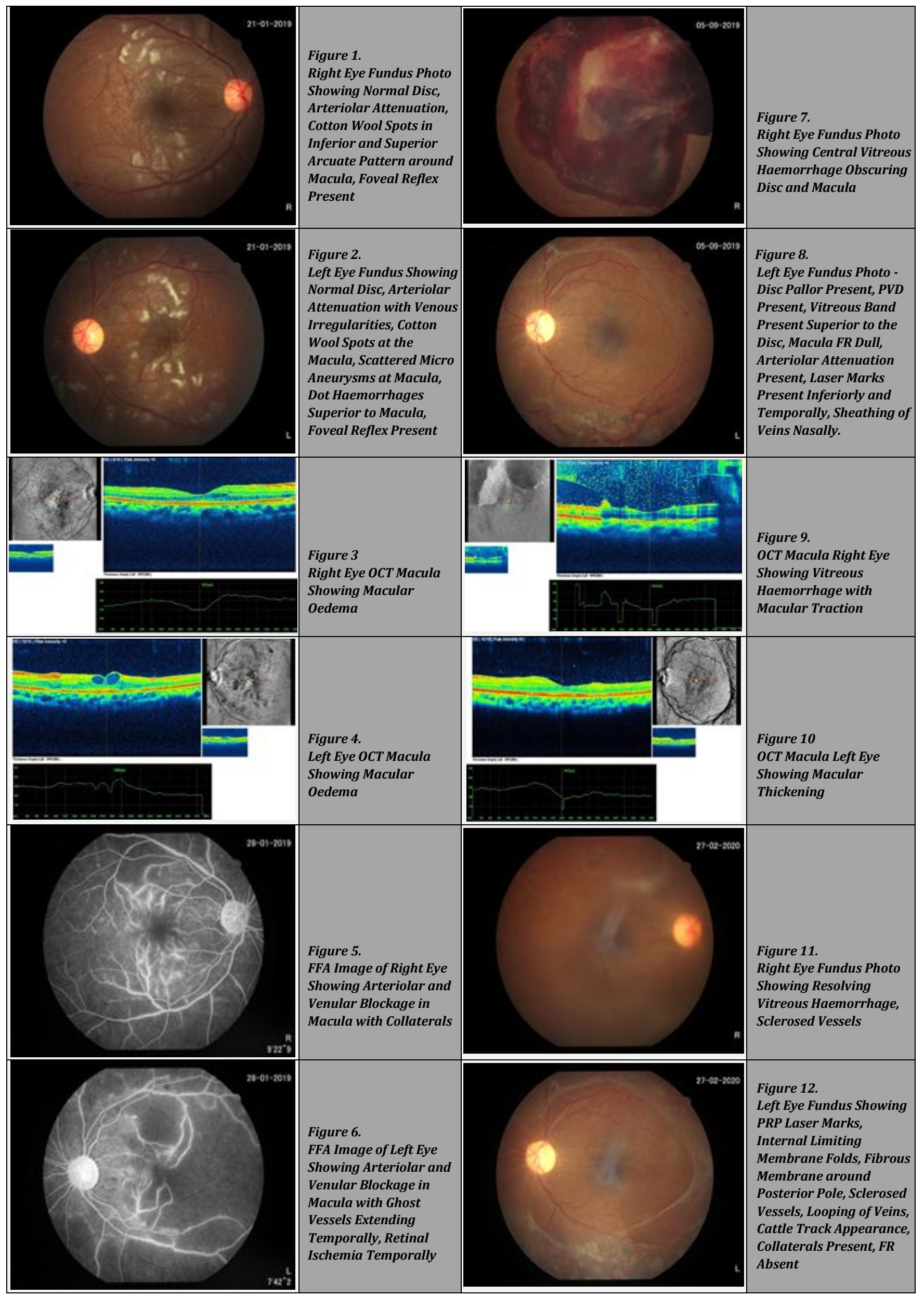




\section{DISCUSSION OF MANAGEMENT}

Since there was vitreous haemorrhage in right eye, 2 doses of intravitreal ranibizumab were administered in both eyes. Vitreous haemorrhage resolved gradually (Figure 11). Injection cyclophosphamide 6 cycles have been administered over 6 months. Sectoral PRP was done in both eyes. Injection methyl prednisolone $500 \mathrm{mg}$ for 3 days was given followed by prednisolone $30 \mathrm{mg} /$ day. Patient is feeling better and is now on regular follow up.

\section{DISCUSSION}

SLE is a chronic, autoimmune, multisystem, inflammatory disorder. ${ }^{1}$ Its prevalence in India is 3 in $1,00,000 .{ }^{8}$ Ocular involvement is rare and is seen in only about one third of the SLE patients. 5 Ocular manifestations in SLE are due to deposition of immune complex in the blood vessels of conjunctive, ciliary body, basement membrane of cornea, retina, choroid, sclera, peripheral nerves of conjunctiva leading to vasculitis and thrombosis. Ocular manifestations include periorbital oedema, vasculitis, myositis, and panniculitis, keratoconjunctivitis sicca, Episcleritis, Corneal epitheliopathy, Lupus retinopathy.1,9,10 Most common presentation of SLE is keratoconjunctivitis sicca, which if left untreated can lead to scarring, ulceration, corneal epitheliopathy, filamentary keratitis.7,11 Rarely peripheral ulcerative keratitis can be seen. They usually present with proptosis, enophthalmos, orbital pain, blurred vision, chemosis, and restriction of extraocular movements. Discoid lupus erythematosus may be seen on the eyelids. Pro inflammatory markers such as IL - 17 may be seen in the tear film in patients with SLE. Systemic association is more common in children with episcleritis than adults. There can be non-perfusion of globe and extraocular muscle due to vasculitis. There can be irreversible visual loss due to optic nerve ischemia and neovascular glaucoma.1,12 Vasculitis of retinal capillaries with local microinfarction is the characteristic finding of lupus retinopathy. ${ }^{5}$ Large vessel occlusion ( branch or central, arteriole or vein) is more common in SLE with APS (anti phospholipid antibody syndrome). ${ }^{5}$

Ocular manifestations are not included in the diagnostic criteria but it accurately indicates active, occult or overt lupus. ${ }^{5}$ It has been noted that survival rate is significantly reduced in SLE patients with retinopathy than SLE patients without retinopathy. ${ }^{2}$ Most common fundus findings in SLE are retinal haemorrhage, cotton wool spots, optic disc oedema and vasculopathy.3,13,14,15 SLE affecting the smaller retinal arteries and arterioles cause a relatively rare form of severe vaso-occlusive retinopathy, histologically it has been found that there were no signs of true inflammation but the presence of fibrinoid change in the vessel wall. ${ }^{3}$

Most common cause of vision threatening complication of SLE is lupus retinopathy, which is seen in about $29 \%$ of patients with active disease. ${ }^{1}$ Most common manifestation of lupus retinopathy is microangiopathy, where small intraretinal haemorrhage and cotton wool spots can be seen, this occurs due to deposition of immune complexes in the vessel wall along with micro emboli. ${ }^{15}$ On fluorescein angiography it is seen as increased permeability of arterioles and venules with capillary non perfusion.1,16

There can be neovascularization which can lead to tractional retinal detachment and vitreous haemorrhage. Early and aggressive management is essential in such cases to save the vision of the patient. A few differential diagnoses include vasculitis, mixed connective tissue disease, rheumatoid arthritis, cytomegalovirus infection, rhupus, systemic sclerosis, Sjogren's syndrome, Bechet's syndrome, myelodysplastic syndrome. ${ }^{17}$

Treatment options for SLE include NSAID (nonsteroidal anti-inflammatory drugs), corticosteroids, antimalarials, immunomodulatory and biologic agents. ${ }^{1}$ Systemic management should be started in cases with severe ocular inflammation, retinal vasculitis, choroiditis, scleritis, and optic neuritis. The main objective of the treatment is to reduce the autoantibody level and suppress immune activity. ${ }^{1}$ Mainstay of treatment for SLE is corticosteroids. ${ }^{18,19}$ They inhibit both innate and adaptive immune response. A high correlation has been seen between CNS vasculitis and retinal vasculitis. ${ }^{20}$ and choroiditis and nephritis. ${ }^{1,21}$ Antimalarials such as chloroquine and hydroxychloroquine are more commonly used. Other treatment options include azathioprine, cyclosporine $\mathrm{A}$, methotrexate, mycophenolate mofetil, cyclophosphamide and chlorambucil. ${ }^{1}$ Presence of choroidopathy and retinopathy is considered a poor prognostic factor in both systemic and ophthalmic morbidity. ${ }^{1}$

\section{CONCLUSIONS}

Posterior segment findings are common in SLE and is a direct reflection of the systemic vascular damage and hence is very important in the management and prognosis of the condition. SLE can manifest with retinal vasculitis causing ischemic retinopathy. Early detection of retinal vasculitis can help in preventing vision threatening complications.

Financial or other competing interests: None.

Disclosure forms provided by the authors are available with the full text of this article at jemds.com.

\section{REFERENCES}

[1] Palejwala NV, Walia HS, Yeh S. Ocular manifestations of systemic lupus erythematosus: a review of the literature. Autoimmune Dis 2012;2012:290898.

[2] Shrestha R, Sitaula RK, Karki P, et al. Combined intravitreal bevacizumab and dexamethasone in bilateral lupus retinopathy. Int Med Case Rep J 2019;12:329-33.

[3] Ho TY, Chung YM, Lee AF, et al. Severe vaso-occlusive retinopathy as the primary manifestation in a patient with systemic lupus erythematosus. J Chin Med Assoc 2008;71(7):377-80.

[4] Tikly M, Navarra SV. Lupus in the developing world-is it any different? Best Pract Res Clin Rheumatol 2008;22(4):643-55.

[5] Bhojwani D, Rishi P, Majumder PD, et al. Systemic lupus erythematos us retinopathy in a 32-year old female: report of a case. Indian J Ophthalmol 2014;62(9):951-2.

[6] Corbin JF. Systemic lupus erythematosus. In: Jakobiec FAT, Albert DM, eds. Principles and Practice of 
Ophthalmology. Philadelphia, PA: WB Saunders 1994:4429-36.

[7] Mills JA. Systemic lupus erythematosus. N Eng J Med 1994;330(26):1871-9.

[8] Kumar A. Indian guidelines on the management of SLE. Indian J Rheumatol 2002;10:80-96.

[9] Tuffanelli DL, Dubois EL. Cutaneous manifestations of systemic lupus erythematosus. Arch Dermatol 1964;90(4):377-86.

[10] Jensen JL, Bergem HO, Gilboe IM, et al. Oral and ocular sicca symptoms and findings are prevalent in systemic lupus erythematosus. J Oral Pathol Med 2007;28(7):31722.

[11] Messmer EM, Foster CS. Vasculitic peripheral ulcerative keratitis. Surv Ophthalmol 1999;43(5):379-96.

[12] Stavrou P, Murray PI, Batta K, et al. Acute ocular ischaemia and orbital inflammation associated with systemic lupus erythematosus. Br J Ophthalmol 2002;86(4):474-5.

[13] El-Asrar AMA, Herbort CP, Tabbara KF. Retinal vasculitis. Ocul Immunol Inflamm 2005;13(6):415-33.

[14] Gold DH, Morris DA, Henkind P. Ocular findings in systemic lupus erythematosus. $\mathrm{Br} \mathrm{J}$ Ophthalmol 1972;56(11):800-4.
[15] Ushiyama O, Ushiyama K, Koarada S, et al. Retinal disease in patients with systemic lupus erythematosus. Ann Rheum Dis 2000;59(9):705-8.

[16] Lanham JG, Barrie T, Kohner EM, et al. SLE retinopathy: evaluation by fluorescein angiography. Ann Rheum Dis 1982;41(5):473-8.

[17] Mallappa S, Kumar K, Hazra S, et al. A case report of retinal vasculitis in systemic lupus erythematosus. J Evid Based Med Healthc 2017;4(76):4503-6.

[18] Lo MS, Tsokos GC. Treatment of systemic lupus erythematosus: new advances in targeted therapy. Ann N Y Acad Sci 2012;1247(1):138-52.

[19] Glueck CJ, Wang P, Hutchins R, et al. Ocular vascular thrombotic events: central retinal vein and central retinal artery occlusions. Clin Appl Thromb Hemost 2008;14(3):286-94.

[20] Jabs DA, Fine SL, Hochberg MC, et al. Severe retinal vasoocclusive disease in systemic lupus erythematosus. Arch Ophthalmol 1986;104(4):558-63.

[21] Baglio V, Gharbiya M, Balacco-Gabrieli C, et al. Choroidopathy in patients with systemic lupus erythematosus with or without nephropathy. J Nephrol 2011;24(4):522-9. 